\title{
THE RELATIONSHIP BETWEEN STRATEGIC MANAGEMENT PRACTICES AND THE GROWTH OF SMALL AND MEDIUM ENTERPRISES (SMES) IN GHANA
}

\author{
Alex ADDAE-KORANKYE ${ }^{1 *}$, Bernard Agyei ARYEE ${ }^{2}$ \\ ${ }^{1}$ Central Business School, Central University, Accra, Ghana \\ ${ }^{2}$ USAID, Accra, Ghana
}

Received 21 April 2020; accepted 13 January 2021

\begin{abstract}
The main goal of the study was to examine or investigate the impact of strategic management practices on the growth of SMEs in Ghana. Purposive sampling technique was employed to sample 190 SMEs in Accra, though 150 SMEs responded to the questionnaire. With the help of SPSS version 22, Multiple regression analysis was conducted to assess the impact of strategic management practices on the performance and hence growth of SMEs in Ghana. The study revealed a significant positive relationship between strategy formulation and growth of SMEs in Ghana. The study also found a significant positive relationship between strategy implementation and the growth of SMEs in Ghana, but found a negative relationship between strategy evaluation and growth of SMEs in Ghana. However, overall, the study found a positive relationship between effective and efficient application of strategic management practices and the growth of SMEs in Ghana. As a contribution to policy and practice, the study recommended among others that policy makers, managers and owners of Small and Medium Enterprises (SMEs) should employ strategic management experts especially in the field of strategy evaluation to enhance the quality of their strategy evaluation process so as to positively influence the performance and growth of SMEs.
\end{abstract}

Keywords: growth, Small Medium Enterprises (SMEs), strategic management, strategy formulation, strategy implementation, strategy evaluation.

JEL Classification: D2, M2, M1, L1.

\section{Introduction}

Small and Medium Enterprises (SMEs) are increasingly recognised as important drivers of economic growth, productivity, innovation and employment, and are widely accepted as a key aspect of economic dynamism (Hisrich, 2014). These small businesses dominate the African business environment because they account for almost 90 percent of all businesses in Africa and they are the engine of growth through their ability to generate employment, increase income and hence increase the Gross Domestic Product (GDP) of countries (Muriithi, 2017). In Ghana, for instance, the small businesses account for 90 percent of the business market, they employ 85 percent of the Ghanaian workforce and contribute about 70 percent of the country's Gross Domestic Product (GDP). Small and Medium Enterprises (SMEs) continue to be very important to many developing countries; they form $99 \%$ of total establishments, $67 \%$ of employment, and contribute over
$50 \%$ of value added to Gross Domestic Product (GDP) within the OECD community (OECD, 2010).

Owing to the contribution of SMEs in Ghana and the world at large, they are required to be profitable, survive, grow and hence remain sustainable and competitive. However, SMEs face various challenges in their quest to achieve the above and expand their market share. Among these challenges, is management ineptitude, which often leads to the collapse of many SMEs. To address the challenge of management, SMEs are encouraged to adopt strategic management practices and strategies in their administration. Strategic management according to Bryson (2011) is simply a tool used as a guide to the attainment of the business vision. It stipulates the procedural steps and programmes an organisation seeks to pursue to move the firm from its current state to an expected future outcome in the process of time. It focuses on the best and most effective means to reach organisational success.

${ }^{*}$ Corresponding author. E-mail: ogyabonkofi@gmail.com

Copyright $\odot 2021$ The Author(s). Published by Vilnius Gediminas Technical University

This is an Open Access article distributed under the terms of the Creative Commons Attribution License (http://creativecommons.org/licenses/by/4.0/), which permits unrestricted use, distribution, and reproduction in any medium, provided the original author and source are credited. 
Strategic management practices adopted by an SME can affect its performance and hence its growth. Strategic management practices can be adopted in terms of organisational structure, resource allocation, corporate culture, leadership and conflict management. All of these aspects are essential to performance, growth and hence sustainability of SMEs. This study therefore examines the relationship or correlation between strategic management practices and growth of SMEs in Ghana. In other words, the study examines the impact of strategic management practices (strategy formulation, strategy implementation, and strategy evaluation) on the growth of SMEs in Ghana.

Most studies on the relationship between strategic management practices and organisational growth or performance have concentrated on large firms Lawal et al. (2012) cited by Ali and Qun (2019). However, the main challenge lies with the small firms which do not have enough resources and capacity to formulate, implement and evaluate strategic management practices. The application of strategic management practices is so crucial not only to large firms but more importantly to SMEs because of their contribution to employment and hence economic growth especially in developing countries. The study therefore examined the relationship between strategic management practices and the growth of SMEs in Ghana. Specifically the study sought to examine the correlation between strategy formulation, strategy implementation, strategy evaluation and the growth of SMEs in Ghana.

Available literature is not very clear on the relationship between strategic management practices and the growth of SMEs. Specifically, while some authors find significant positive relationship between strategy formulation and the growth of SMEs, other studies report no significant impact. A similar results occurs on the relationship between strategy implementation and the growth of SMEs. Though a number of authors claim a significant positive correlation between strategy implementation and the growth of SMEs, others find no significant relationship. Finally while some literature report a significant positive relationship between strategy evaluation and the growth of SMEs, other findings claim no significant effect. What is the situation in Ghana? It is this gap which the study sought to fill. Based on the above, the study sought to achieve the following specific objectives:

- To find out the relationship between strategy implementation and the growth of Small and Medium Enterprises (SMEs) in Ghana.

- To determine the correlation between strategy implementation and the growth of SMEs in Ghana.

- To investigate the effect of strategy evaluation on the growth of SMEs in Ghana.

- To what extent does strategic management practices influence the growth of Small and Medium Enterprises (SMEs) in Ghana? Is the relationship between strategic management practices and the growth of SMEs in Ghana positive or negative or no relationship at all?
The study used purposive sampling technique to sample 190 respondents, while questionnaire was used to solicit information from the SMEs. Further, with the help of Statistical Product and Service Solution (SPSS) Ordinary Least square regression was used to analyse the data.

The following is the structure of the article: Introduction, Literature review, Research Methods (Methodology), Results, Discussion and Conclusions.

\section{Literature review}

\subsection{The concept and definition of strategic management}

There is no single definition of strategic management, which is generally acceptable (Markiewicz, 2011). However, Thompson and Strickland (2003) defined strategic management as the process whereby managers establish an organisation's long-term direction, set specific performance objectives, develop strategies to achieve these objectives in the light of all the relevant internal and external circumstances, and undertake to execute the chosen action plans. Sababu (2007) asserts that strategic management also encompasses the development of long term plans for efficient management of environmental opportunities and threats in line with the organisational strengths and weaknesses. According to Pearce and Robinson (2007), strategic management involves a combination of decisions and actions that guide the formulation and implementation of plans intended to achieve organisational objectives. It is the art and science of formulating, implementing and evaluating cross-functional decisions that enable an organisation to achieve its objective. This definition implies strategic management focuses on integrating management, marketing, finance/accounting, production/operations, research and development, and computer information systems to achieve organisational success.

Strategic management is a complex subject which has no right answers but has clear-cut underlying principles. Different strategic management authors and researchers raise the question: "Why do some companies succeed while others fail?" Wheelen and Hunger (2012) argue that organisations succeed if their strategies are appropriate for the circumstances they face. Strategic management is the process and approach of specifying an organisation's objectives, developing policies and plans to achieve and attain these objectives, and allocating resources to implement the policies and plans. In other words, strategic management can be seen as a combination of strategy formulation, implementation and evaluation (David, 2011). According to Abdiwali (2019) strategic management defines the purpose of the organisation and the plans and actions to achieve that purpose. It is that set of managerial decisions and actions that determine the long term performance of a business enterprise. It involves formulating and implementing strategies that will help in aligning the organisation and its environment to achieve organisational goals. In short, strategic management provides overall direction to an organisation. 
The success of strategic management practices to a large extent depends on the effectiveness of strategy formulation, strategy implementation, and strategy evaluation (Ali \& Qun, 2019).

Thompson and Strickland (2003) define strategy formulation as a phase or sub-process of strategic management in which a firm creates its direction, defines its objectives and set a course for the organisation to follow. It starts with environmental scanning whose purpose or objective is to appraise the important factors that would affect both now and the future development of the firm as well as determining the specific factors of influence in the strategic formulation process (Beal, 2000). The environment of an organisation usually consists of two aspects: the internal environment and the external environment. According to Beal (2000), the internal environment of the organisation which shows the parameters within the company consists of strengths and weaknesses, the culture, structure and resources of the company. The external environment on the other hand can be divided into general and specific environment. The general environment context which is also called macro- environment are those factors that could affect all firms in a particular social environment, and which always has a direct impact on firms. The SLEPT module, which includes social, legal, economic, political, and technological environment can be used in the analysis of this environment, while the specific environment consists of micro-environmental factors that have a direct impact on a specific firm (Beal, 2000). These factors include government, competitors, creditors, employees, industry associations and local communities.

The strategy formulation process conjoins the strengths and weaknesses internally to effectively manage the opportunities and threats externally (Fowler \& Hope, 2007).

After the formulation of a strategy, it is necessary to implement it. The implementation of the strategy is to promote and develop programmes to put the strategies and policies that were formulated into action (Wheelen \& Hunger, 2012). It has to do with managerial interventions that brings organisational actions in line with strategic intention (Woodridge \& Floyd, 1990). It displays the finishing result of the organisation's effort on strategy and also depicts the tendency of the organisation's development in the future. As reported by Karami (2007) previous studies have shown that the structure of the organisation, leadership and human resources (employees) play an important role in the implementation of the strategy.

Strategy can neither be formulated nor adjusted to changing circumstances without a process of strategy evaluation. Whether performed by an individual or as part of an organisational review procedure, strategy evaluation forms an essential step in the process of guiding an enterprise (Glueck, 1980). Strategic evaluation is based on the belief that an organisation should continually monitor internal and external events and trends so that timely changes can be made as needed (Aluko et al., 2004).

Wheelen and Hunger (2012) submitted that results of strategy evaluation are essential for further action if the process is showing any problems that affect the functioning of the firm towards its goal. Therefore, firms need to evaluate their strategies on a continuous basis (King'ola, 2001; Tunji, 2013), so that corrective action could be taken to eliminate the problems that hinder the achievement of a firm's objectives (David, 2011).

\subsection{Strategic management practices of SMEs}

The success of strategic management practices and hence the growth/performance of SMEs depends to a large extent on the effectiveness of strategy formulation, strategy implementation, and strategy evaluation (Ali \& Qun, 2019). However the adoption of strategic management practices among SMEs remains poor. Owners and managers of SMEs rarely articulate the business strategy or engage in any formal planning (Njanja, 2009). There is however a strong relationship between the owner/manager and strategy pursued by SMEs. The strategy chosen will mostly reflect the priorities of the owner (Carter \& Jones-Evans, 2006). Although strategic management has mostly been applied in large organisations, it cannot be ignored in SMEs. The environment in which the Ghanaian SMEs exists is very competitive and the firms need to develop strategies to enable them grow and hence give them competitive advantage. With increasing challenges in the business environment, managers of SMEs must have the capability to adapt and restructure the enterprises to address constraints facing them. As asserted by Pillania (2008) SMEs need to adopt superior strategic management practices to enable them grow, remain sustainable and achieve competitive advantage.

According to Njanja (2009) SMEs spend almost twice as much of their research and development budget on fundamental research as do large firms and are more innovative per employee than large firms. The reasons for lack of strategic management practices in many SMEs vary from lack of enough time to prepare the plans, unfamiliarity with strategic planning, lack of skills and lack of trust and openness on the part of owners. As opined by Lawal et al. (2012) the strategic management practices of SMEs should entail relatively short planning horizon, be informal and not overly structured, encourage participation of employees and outside parties, avoid early setting of objectives as it will interfere with creative thinking and focus on strategic thinking, and not just planning. For this reason firms that pursue sustainable strategic management base the formulation, implementation, and evaluation of their strategies on an analysis of the ecological issues they face, the values they hold that support sustainability and growth, and the ecological interests of their stakeholders (Nyariki, 2013). 


\subsection{The impact of strategic management practices on the growth of small and medium enterprises (SMEs)}

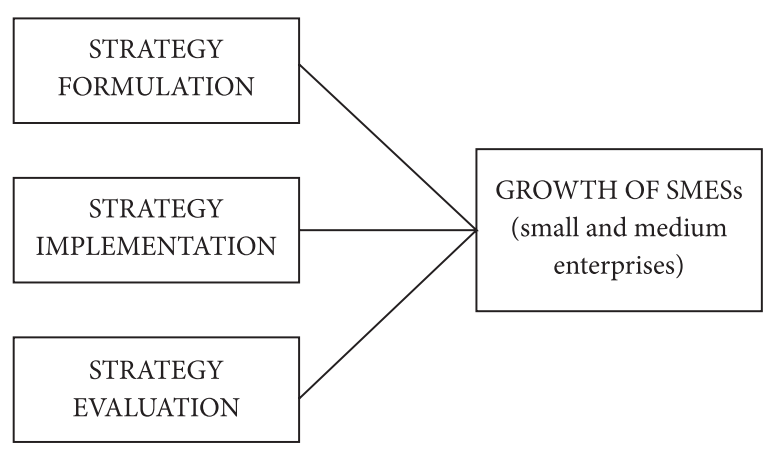

Figure 1. The relationship between strategic management practices and the growth of SMEs (source: author's own creation)

The above framework (Figure 1) indicates the relationship between strategic management practices (strategy formulation, strategy implementation, and strategy evaluation) and the growth of SMEs.

As stated earlier, the success of strategic management and hence the growth/performance of SMEs depends to a large extent on the effectiveness of strategy formulation, strategy implementation, and strategy evaluation (Ali \& Qun, 2019). Over the years, empirical research in strategic management has been centered on identifying which set of strategies and practices would enable organisations to achieve growth and hence economic success. An efficient and effective strategic management system can lead to an increase in desired results be it economic or social growth.

A number of studies related to strategic management, performance, growth and sustainability have been done in Ghana and internationally. Lawal et al. (2012) studied the effect of strategic management on organisational performance. The study found that the adoption of strategic management techniques improved organisational performance and improved relative standing of organisation that was with different societal and political issues. Another study conducted in Nigeria by Ajao and Grace (2012) cited by Mohamud et al. (2019), using questionnaire to sample 283 organisations also found that effective strategic planning and effective implementation indeed has a positive impact on organisational performance and growth. Furthermore, a similar study by Mohamud et al. (2019) in Somalia revealed a positive relationship between growth/ performance of SMEs and effective implementation of strategic management practices.

Heugens (2003) studied strategic issues in management and organisational outcomes and assessed whether strategic issues and management activities contribute anything worthwhile to corporate performance, growth and sustainability by reporting two studies on the issues in management strategies of Dutch food firms during the introduction of genetically modified ingredients. The study found that implementation of issues of management activities by firms that were exposed to societal or political predicaments significantly and positively influenced organisational outcome variables.

Muogbo (2013) cited by Mohamud et al. (2019), studied the impact of strategic management on organisational growth and development (a study of selected manufacturing firms in Anambra state). The results from the analysis indicated that strategic management was not common among the manufacturing firms; that the adoption of strategic management had significant effect on competitiveness and growth and also influences manufacturing firms; that strategic management had effect on employee's performance and that its adoption had significantly increased organisational productivity of manufacturing firms. Again, strategic management enhances structural development of manufacturing firms. The study concluded that though strategic management was not common in business practices among manufacturing firms in Anambra State, it was identified as veritable tool for improving the competitiveness, performance levels, and structural development of manufacturing firms in Anambra State in particular and Nigeria in general.

Yunus et al. (2010) studied strategic management practices and corporate performance of selected small business enterprises in Lagos metropolis. The study established that strategic management has effect on the market share of small enterprises studied. In addition, implementation of strategic management was found to have positive relationship with organisational profitability and hence growth. However, for the positive effect to be felt, the study recommended that appropriate strategic planners, strategic situation, strategic analysis and choice have to be put in place.

Njanja (2009) studied management strategies affecting performance of micro, small and medium enterprises in Kenya. The study found that globalisation factors and other factors external to the businesses such as incentives, regulation and policy issues, and infrastructure had very high effects on the management structures, systems and other internal factors of the firm. This study however did not show any clear cut relationship between management practices and performance.

Otieno (2013) studied strategic issue in management practices by small and medium enterprises in Mombasa County using descriptive survey design and data collected from primary sources using questionnaire. The study found profitability as the most important performance measure in SMEs, followed by market share, innovation and liquidity respectively. Further, majority of organisations perceived strategic issue in management to the future success and growth of organisations as very important and essential confirming that SMEs in Mombasa County were aware of the importance of strategic issue in management in the success of an organisation. The study also found that environmental as well as managerial factors influenced strategic issue in management practices by SMEs in Mombasa County. 
Green and Medlin (2003) for instance developed a scale to measure mission statement excellence and then tested its connection with financial performance. They also arrived at a positive and significant relationship between strategic management practices and organisational growth. Further, Ali and Qun (2019) examined the relationship between strategic management practices and the growth of SMEs in Bangladesh and found a positive correlation between strategic management practices and growth/performance of SMEs. Specifically, the study found that $89 \%$ of the variance in the growth/performance of SMEs is due to effective application of strategic management practices.

\subsection{Hypotheses}

From the literature and previous studies the following hypotheses were framed and tested.

a. The impact of Strategy formulation on the growth of SMEs in Ghana.

H0: Strategy Formulation has no significant impacts on the growth of Small and Medium Enterprise (SMEs) in Ghana.

H1: Strategy Formulation has significant positive impact on the growth of SMEs in Ghana.

b. The impact of Strategy implementation on the growth of SMEs in Ghana.

H0: Strategy Implementation has no significant impact on the growth of SMEs in Ghana.

$\mathrm{H} 1$ : Strategy Implementation has a significant positive impact on the growth of SMEs in Ghana.

c. The impact of Strategy Evaluation on the growth of SMEs in Ghana.

H0: Strategy Evaluation has no significant impact on the growth of Small and Medium Enterprise (SMEs) in Ghana.

$\mathrm{H1}$ : Strategy Evaluation has a significant positive impact on the growth of SMEs in Ghana.

\section{Research methods}

\subsection{Research design, sample and data collection}

The study adopted quantitative research design. The population included all registered SMEs in the Central Business district of Accra, the capital of Ghana which have been in operation for at least three years. The estimated population was 500 SMEs as at the time of the study. Based on Slovin's formula of sample determination $\left\{\mathrm{n}=\mathrm{N} /\left(1+\mathrm{Ne}^{2}\right)\right\}$, Tejeda and Punzalan (2012), purposive sampling technique was employed to sample 190 registered SMEs which have been in operation for at least 3 years for the study. The study used purposive sampling because the study was interested in only registered SMEs which have been in operations for at least 3 years. These are the respondents who could provide the necessary data or information to address the objectives of the study. Out of the sample of 190 SMEs one hundred and fifty (150) filled or responded to the questionnaire. Questionnaire was used as the data collection instrument because it enabled the researcher to reach a large number of sampled SMEs within a short period of time.

Sample Size Calculation $=\left\{\mathrm{n}=\mathrm{N} /\left(1+\mathrm{Ne}^{2}\right)\right\}$,

where: $\mathrm{n}=$ minimum sample size; $\mathrm{N}=$ Population, $\mathrm{e}=$ margin of error. Using a margin of error of $5 \%$, and population of 500; the minimum sample size $=500 / 1+500\left(0.05^{2}\right)=$ 181. The study therefore used a sample size of 190 but those who responded to the questionnaire were 150 SMEs.

\subsection{Data analysis}

Data obtained were checked for errors and inconsistencies. The data were then coded and entered into the computer. The statistical product and service solution (SPSS) version 22 was used to capture the data and run multiple regression for the analysis.

Data concerning the firms' general background information, nature of strategic management practices applied and factors influencing choice of strategy were coded and analysed. As said earlier, multiple regression analysis was run to determine the relationship between strategic management variables and the growth of SMEs. As indicated above the variables used to define or represent strategic management practices are strategy formulation, strategy implementation, and strategy evaluation. The relationship between the dependent and independent variables was explained by:

$$
G=f\left(X_{1}, X_{2}, X_{3}\right) .
$$

The function (equation 1) means that Growth $(G)$ is a function of strategy formulation $\left(X_{1}\right)$, strategy implementation $\left(X_{2}\right)$ and strategy evaluation $\left(X_{3}\right)$. In other words, growth of SMEs depends on strategy formulation, strategy implementation, and strategy evaluation. The multiple regression model (econometric model) developed by the study took the following form:

$$
G=\beta_{0}+\beta_{1} X_{1}+\beta_{2} X_{2}+\beta_{3} X_{3}+e,
$$

where: $G$ is Growth as measured by composite score of financial and nonfinancial performance indicators; $X_{1}$ is strategy formulation; $X_{2}$ is Strategy Implementation; $X_{3}$ is Strategy Evaluation; $\beta_{1}, \beta_{2}, \beta_{3}$ are the coefficients, which represent the change in growth when there is a unit change in strategy formulation, strategy implementation, and strategy evaluation respectively; $\beta_{0}=$ a constant, which represents growth of SMEs when there is no adoption of strategic management practices; $e$ is the error term.

\subsection{Validity and reliability}

Cronbach Alpha which was computed to test the reliability of the impact of strategic management practices on the growth of SMEs in Ghana revealed a figure of 0.856 which indicates a very strong internal consistency because according to Ursachi et al. (2015) a reliability of 0.70 or higher is sufficient proof of reliability in the social sciences. 
On the issue of validity, the questionnaire which was used to collect data for the study was pre-tested and refined to remove all ambiguities and hence it measured what it was supposed to measure. In addition to that, the researcher took time to explain some aspects of the questionnaire to those SMEs who requested for clarity to ensure that all their responses were accurate.

\section{Results}

The study used Ordinary Least Square (OLS) regression to examine the relationship between strategic management practices and the growth of SMEs in Ghana. The variables used to define strategic management practices are strategy formulation, strategy implementation, and strategy evaluation.

\subsection{Multi collinearity assumption}

Multi collinearity test was conducted to determine if there exists correlation among the independent variables (Strategy formulation, strategy implementation and strategy evaluation). Tolerance scores and Variance Inflation Factors (VIF) were estimated as shown in Table 1.

As shown in Table 1, the tolerance scores and Variance Inflation Factor (VIF) for all the variables are above 0.12 and below 10 respectively. This therefore indicates that there existed no multicollinearity in the estimated Ordinary Least Square (OLS) regression model. The multicollinearity assumption is met.

Table 1. Collinearity statistics (source: Field Data, 2019)

\begin{tabular}{|l|c|c|}
\hline \multirow{2}{*}{ Variables } & \multicolumn{2}{c|}{ Collinearity Statistics } \\
\cline { 2 - 3 } & Tolerance Score & VIF \\
\hline Strategy Formulation & 0.158 & 7.799 \\
\hline $\begin{array}{l}\text { Strategy } \\
\text { Implementation }\end{array}$ & 0.178 & 5.605 \\
\hline Strategy Evaluation & 0.153 & 6.516 \\
\hline
\end{tabular}

\subsection{Model summary and Analysis of Variance (ANOVA)}

\subsubsection{Model summary}

Table 2 presents the results on the summary of the estimated model for the study. Correlation coefficient (R), $\mathrm{R}$-square and adjusted R-square are estimated.

As shown in the Table 2, the Adjusted R-square of the estimated model is $74 \%$ thus 0.740 . This indicates that $74 \%$ of the changes in the dependent variable (growth) are explained by predictor variables Strategy Formulation, Strategy Implementation and Strategy Evaluation. Thus, the estimated model has a very good predictive power.

Table 2. Model summary (source: Field Data, 2019)

\begin{tabular}{|c|c|c|c|}
\hline Model & $\mathrm{R}$ & $\mathrm{R}$ Square & Adjusted R Square \\
\hline 1 & 0.865 & 0.748 & 0.740 \\
\hline
\end{tabular}

\subsubsection{Analysis of Variance (ANOVA)}

Table 3 presents the results of the ANOVA for examining the significance of the estimated model. Sum of Squares (SS), mean squares (MS), F-Statistics and P-value were estimated.

As shown in Table 3 the F-statistics of the estimated model is 94.788 with a P-value of 0.000 . Since the P-value is less than the $5 \%(0.05)$ significance value, the study concludes at $5 \%$ significance level that the estimated model is significant for examining the relationship between strategic management practices and the growth of Small and Medium Enterprises (SMEs) in Ghana.

Table 3. ANOVA statistics (source: Field Data, 2019)

\begin{tabular}{|c|l|c|c|c|c|c|}
\hline \multicolumn{2}{|c|}{ Model } & $\begin{array}{c}\text { Sum of } \\
\text { Squares }\end{array}$ & df & $\begin{array}{c}\text { Mean } \\
\text { Square }\end{array}$ & F & $\begin{array}{c}\text { Sig. } \\
\text { (P-value }\end{array}$ \\
\hline \multirow{2}{*}{1} & Regression & 460.527 & 3 & 153.509 & 94.788 & .000 \\
\cline { 2 - 7 } & Residual & 155.473 & 96 & 1.620 & & \\
\cline { 2 - 7 } & Total & 616.000 & 99 & & & \\
\hline
\end{tabular}

Table 4 presents the results of the estimated Ordinary Least Square (OLS) Regression Model for examining the impact of strategic management practices on the growth of Small and Medium Enterprises (SMEs) in Ghana. Coefficient estimates, Robust Standard Errors (Robust Std. Error), t-statistics and Probability Values (P-value) were estimated.

Table 4. Estimated OLS regression model for the dependent variable sustainability (source: Field Data, 2019)

\begin{tabular}{|l|c|c|c|c|}
\hline \multicolumn{1}{|c|}{ Regressors } & $\begin{array}{c}\text { Coeffi- } \\
\text { cients }\end{array}$ & $\begin{array}{c}\text { Robust Std. } \\
\text { Error }\end{array}$ & $\mathrm{t}$ & P-Value \\
\hline $\begin{array}{l}\text { Strategy } \\
\text { Formulation }\end{array}$ & 0.11 & 0.05 & 2.35 & 0.021 \\
\hline $\begin{array}{l}\text { Strategy } \\
\text { Implementation }\end{array}$ & 0.19 & 0.10 & 10.47 & 0.000 \\
\hline $\begin{array}{l}\text { Strategy } \\
\text { Evaluation }\end{array}$ & -0.13 & 0.06 & -2.25 & 0.027 \\
\hline Constant & -5.27 & 1.97 & -2.68 & 0.009 \\
\hline
\end{tabular}

As shown in Table 4, the variable Strategy Formulation has coefficient of 0.11 and a P-value of 0.021 . This indicates that holding other variables constant a percentage $(1 \%)$ increase in Strategy Formulation, increases the growth of Small and Medium Enterprises (SMEs) in Ghana by $0.11 \%$. This relationship is significant at $5 \%$ significance level since the P-value of 0.021 is less than the 5\% (0.05) significance value.

In addition, the variable Strategy Implementation has coefficient of 0.19 and a P-value of 0.000 . This indicates that "other things being equal" for a percentage (1\%) increase in Strategy Implementation, the growth of Small and Medium Enterprises (SMEs) in Ghana increases by $0.19 \%$. This relationship is also significant at $5 \%$ significance level since the P-values 0.000 is less than the $5 \%$ (0.05) significance value. 
Furthermore, the variables Strategy Evaluation has coefficient of -0.13 and a P-value of 0.027 . This again indicates that holding other variables constant, a percentage $(1 \%)$ increase in Strategy Evaluation, leads to $0.13 \%$ decrease in the growth of Small and Medium Enterprises (SMEs) in Ghana. This relationship is also significant at $5 \%$ significance level since the P-values 0.027 is less than the $5 \%$ significance value 0.05 .

Finally, a constant coefficient of -5.27 which is significant at $5 \%$ significance level with a P-value of 0.009 indicates that when all the independent variables (strategy formulation, strategy implementation, and strategy evaluation) are held constant, the growth of Small and Medium Enterprises (SMEs) in Ghana decreases by $5.27 \%$. In other words, when SMEs do not practice strategic management in their operations, their growth reduces by $5.27 \%$. This implies that the practice of strategic management enhances growth of SMEs in Ghana.

As explained above and also from Table 4, the specific regression equation is:

$$
\mathrm{G}=-5.27+0.11 \mathrm{SF}+0.19 \mathrm{SI}-0.13 \mathrm{SE}+\mathrm{e},
$$

where $\mathrm{G}=$ Growth of SMEs; SF = Strategy Formulation; $\mathrm{SI}=$ Strategy Implementation; SE = Strategy Evaluation; $\mathrm{e}=$ error term, which represents all other factors that influence growth of SMEs.

\section{Discussion}

\subsection{Theoretical contribution}

The study revealed that Small and Medium Enterprises (SMEs) in Ghana adopt strategy formulation, strategy evaluation and strategy implementation as their strategic management practices. The effective and efficient formulation and implementation of strategic management would improve the management of the Small and Medium Enterprise (SMEs) and consequently the productivity, performance, profitability and growth of the Small and Medium Enterprises (SMEs) in Ghana. On the other hand application of strategy evaluation reduces the growth of SMEs in Ghana.

The specific model from the regression output (Table 4) is;

$$
\mathrm{G}=-5.27+0.11 \mathrm{SF}+0.19 \mathrm{SI}-0.13 \mathrm{SE}+\mathrm{e},
$$

where $\mathrm{G}=$ Growth of SMEs; SF = Strategy Formulation; SI = Strategy Implementation; SE = Strategy Evaluation; $\mathrm{e}=$ error term.

The above equation implies that there is a positive relationship between Growth and strategy formulation. Specifically, a one percent increase in Strategy formulation increases growth of SMEs by $0.11 \%$. There is also a positive relationship between strategy implementation and growth of SMEs. From the specific model, a one percent increase in strategy implementation will lead to $0.19 \%$ increase in growth of SMEs. Further, there is a negative relationship between strategy evaluation and growth of SMEs in Ghana. Specifically, a one percent increase in strategy evaluation decreases growth of SMEs by 0.13 . In addition to the above the adjusted R-square of 0.740 means that $74 \%$ of changes in the growth of SMEs in Ghana is due to the application of strategic management practices. The implication is that there is a strong positive relationship between strategic management practices and the growth of SMEs in Ghana.

There are a number of studies from Nigeria, South Africa, Somalia, Kenya, Bangladesh, etc. that confirm or corroborate the findings of the current study. For example, the studies by Lawal et al. (2012), Mahamud et al. (2019), Muogbo (2013), Yunus et al. (2010), Ajao and Grace (2012) in Nigeria revealed a positive relationship between implementation of strategic management practices and performance and hence growth of SMEs.

Secondly, a study by Hieu and Nwachukwu (2019) on strategic management practices and the growth of organisations in Vietnam also confirm the findings of the current study that effective implementation of strategic management practices impact positively on organisations' performance and hence their growth. Ali and Qun (2019) also examined the impact of strategic management practices and the growth of SMEs in Bangladesh and found a positive correlation between strategic management practices and growth/performance of SMEs. Specifically, the study found that $89 \%$ of the variance in the growth/ performance of SMEs was due to effective application of strategic management practices.

Further, Mohamud et al. (2015) studied the effect of strategic management on the growth/performance of organisations, and found a positive relationship. This confirms the findings of the current study. In Kenya, separate studies by Njanja (2009) and Otieno (2013) on the impact of strategic management on organisational performance also found a positive relationship between effective strategic management practices and growth of organisations. These again corroborate the findings of the current study.

Notwithstanding the above, when the strategic management practices; strategy formulation, strategy implementation and strategy evaluation are not effectively and efficiently done by organisations including Small and Medium Enterprises (SMEs) or when they are not implemented at all, the quality, performance and the growth of Small and Medium Enterprises (SMEs) would be affected negatively.

This further implies that as Small and Medium Enterprises (SMEs) effectively increase their strategy formulation and implementation, their performance and growth increases. This is because strategy formulation and implementation enable Small and Medium Enterprises (SMEs) to identify their strengths and weaknesses and efficiently and effectively manage them in line with their organisational goals and objectives. This would enable Small and Medium Enterprises (SMEs) to achieve their short- run and long- run sustainability and growth. The attainment of the goals and objectives of Small and Medium Enterprises 
(SMEs) implies that their productivity, performance, profitability and growth would sustainably increase.

The current study finally assessed the influence of strategy evaluation on the growth of Small and Medium Enterprises (SMEs) in Ghana and revealed that strategy evaluation has a statistically significant negative influence on the growth of Small and Medium Enterprises (SMEs) in Ghana. Thus, for a percentage increase in the strategy evaluation, the growth of Small and Medium Enterprises (SMEs) in Ghana decreases by $0.13 \%$. This could mean that the cost of strategy evaluation by Small and Medium Enterprises (SMEs) in Ghana exceeds the revenue or returns the Small and Medium Enterprises (SMEs) generate which could also mean that SMEs in Ghana lack strategy evaluation experts.

As a result, the more SMEs in Ghana adopt strategy evaluation the more their profitability and growth decreases. Also, the negative influence of strategy evaluation on the growth of Small and Medium Enterprises (SMEs) could be as a result of poor and ineffective adoption of strategy evaluation of Small and Medium Enterprises (SMEs). This would prevent the Small and Medium Enterprises (SMEs) from benefiting positively from their adoption of strategy evaluation. In a similar study conducted by Otieno (2013) it was revealed that when strategic management practices are ineffective, implementation coupled with organisational challenges, could negatively affect the performance of Small and Medium Enterprises (SMEs).

\subsection{Practical contribution}

As contribution to policy and practice, the study has made it clear that effective and efficient application of strategic management leads to growth of SMEs in Ghana. From the above results, strategy formulation has a positive relationship with growth of SMEs. Secondly, there is also a positive relationship between strategy implementation and the growth of SMEs in Ghana. The above should inform policy makers, managers and owners of SMEs in Ghana to employ mechanisms to enhance their application of strategy formulation and implementation in order to improve the performance and hence the growth of SMEs in Ghana. It also means that they should engage experts in the field of strategic management to enhance the performance and hence growth of SMEs.

Secondly, from the results of the study, strategy evaluation has a negative relationship with performance and hence growth of SMEs in Ghana. This should be a concern to policy makers, managers and owners of SMEs. They should employ experts in the field of strategic management especially in the field of strategy evaluation to enhance the quality of strategy evaluation process to improve performance and enhance the growth of SMEs.

\section{Conclusions}

In general, the study has provided insight into the impact of strategic management practices on the performance and the growth of Small and Medium Enterprises (SMEs) in Ghana. In summary, the study found that there is a significant positive relationship between strategy formulation and growth of SMEs, Secondly, the study revealed that strategy implementation and growth of SMEs in Ghana are positively related, implying that "other things being equal", effective implementation of strategic management practices will enhance the growth of SMEs in Ghana. The study however, found that strategy evaluation has a significant negative relationship with growth of SMEs in Ghana.

The findings of the study therefore rejects $\mathrm{HO}$ but support $\mathrm{H} 1$ because strategy formulation and strategy implementation have significant positive relationship with the growth of SMEs, however in the case of strategy evaluation the findings of the study support $\mathrm{HO}$ but rejects $\mathrm{H} 1$ because strategy evaluation has significant negative relationship with the growth of SMEs. However, it can be said that overall the effective application of strategic management practices significantly impact positively on the growth of SMEs in Ghana, and all organisations in general. This is because Adjusted R-square of 0.740 implies that $74 \%$ of the growth of SMEs is due to the application of strategic management practices.

The contributions of this study are enormous. Policy makers, managers and owners of SMEs will be informed by the findings of this study to formulate and implement policies to enhance their strategic management practices in line with strategy formulation and strategy implementation to further increase the performance, profitability, growth and sustainability of SMEs.

Further, policy makers including owners and managers of SMEs will use the findings of this study as a basis to employ strategic management experts especially in the field of strategy evaluation to enhance the quality of their strategy evaluation process so that strategy evaluation positively influence the performance, growth and sustainability of SMEs in Ghana.

Based on the findings of the study Managers/Owners and Policy makers of SMEs will be proactive and embrace the tenets that will enhance strategic planning which will ensure the firm's sustainability and growth in turbulent and unpredictable business environment situations. The responsibility for strategic thinking should be viewed as the responsibility of all managers/policy makers and not just top-level executives alone.

Furthermore, since SMEs in Ghana play a significant role in terms of their contribution to Ghana's economic growth the researcher recommends that the government of Ghana should focus on giving technical assistance to SMEs in the area of strategic planning/strategic management so that they can have significant positive impact on the country's economy growth.

\section{Acknowledgements}

The researchers express their gratitude to the SMEs who spent their valuable time to answer the questionnaire. 


\section{Declaration of conflict of interest}

Authors do not have any conflict of interest.

\section{Funding}

The research was not supported by any external funding.

\section{References}

Abdiwali, K. A. (2019). Effects of strategic management practices on firm performance of medium and large telecommunication companies in Mogadishu, Somalia. International Journals of Academic and Research, 1(2), 57-71.

https://doi.org/10.32898/ibmj.01/1.2article05

Ajao, O. S., \& Grace, M. O. (2012). The effects of strategic planning on corporate performance in university education: A study of Babcock University. Kuwait Chapter of Arabian Journal of Business and Management Review, 2(4).

Ali, M., \& Qun, W. (2019). Strategic management practices and performance of SMEs in Bangladesh. International Journal of Advanced Research, 7(1), 69-78.

https://doi.org/10.21474/IJAR01/8298

Aluko, M., Odugbesan, O., Gbadamosi, G., \& Osuagwu, L. (2004). Business policy and strategy. Remof Themes Limited (Educational Publishers).

Beal, R. M. (2000). Competing effectively: environmental scanning, competitive strategy, and organisational performance in small manufacturing firms. Journal of Small Business Management, 38(1), 27-47.

Bryson, J. M. (2011). Strategic planning for public and non-profit organisations: a guide to strengthening and sustaining organisational achievement. John Wiley \& Sons, NJ.

Carter, S., \& Jones-Evans, D. (2006). Enterprise and small business: principles, practice \& policy (2nd ed.). Pearson Education.

David, F. (2011). Strategic management: concepts and cases (13th ed.). Pearson Education Limited.

Fowler, S. J., \& Hope, C. (2007). Incorporating sustainable business practices into company strategy. Journal of Business Strategy and the Environment, 16(1), 26-38. https://doi.org/10.1002/bse.462

Glueck, W. F. (1980). Strategic management and business policy. McGraw-Hill Inc.

Green, J. K., \& Medlin, B. (2003). The strategic planning process: the link between mission statement and organisational performance. Academy of Strategic Management Journal, 2(1), 23-32.

Heugens, P. P. M. A. R. (2003). Strategic issues in management and organisational outcomes. Utrecht School of Economics, Utrecht University.

Hieu, V. M., \& Nwachukwu, C. E. (2019). Business management. D. A. Tsenov Academy of Economics, Svishtov.

Hisrich, R. D. (2014). Entrepreneurship. McGraw-Hill.

Karami, A. (2007). Strategy formulation in entrepreneurial firms. Ashgate Publishing Limited.

Kingola, S. N. (2001). Challenges of strategic implementation at Geomax Consulting Engineers (GEC) [Unpublished Master Thesis, University of Nairobi], Kenya.

Lawal, F. M., Omone, O. E., \& Oludayo, O. (2012). Effect of strategic issue in management on organisational performance. Transnational Journal of Science and Technology, 2(10), 17-29.

Markiewicz, P. (2011). Change management in the strategic implementation process. Intellectual Economics, 5(2), 257-267.
Mohamud, G. Y., Mohamud, A. S., \& Mohamed, B. H. (2019). The relationship between strategic management and organisational performance in Mogadishu-Somalia. European Journal of Research and Reflection in Management Science, 3(2), $42-51$.

Muogbo, U. S. (2013). The impact of strategic management on organisational growth and development (A study of selected manufacturing firms in Anambra State). IOSR Journal of Business and Management (IOSR-JBM), 7(1), 24-32.

https://doi.org/10.9790/487X-0712432

Muriithi, S. (2017). African Small and Medium Enterprises (SMEs) contributions, challenges, and solutions. European Journal of Research and Reflection in Management Science, 5(1), 36-47.

Njanja, L. (2009). An investigation into management strategies affecting performance of Micro, Small and Medium Enterprises in Kenya [Doctor of Commerce Dissertation, University of South Africa]. South Africa.

Nyariki, R. N. (2013). Strategic Management as a competitive tool in enhancing performance of SMEs in Kenya. MBA Project, University of Nairobi, Kenya.

OECD. (2010). OECD studies on SMEs and entrepreneurship $S M E s$, entrepreneurship and innovation. OECD Publishing.

Otieno, M. (2013). Strategic issue management practices by Small and Medium Enterprises in Mombasa County, Kenya. MBA Project, University of Nairobi, Kenya.

Pearce, J. A., \& Robinson, R. B. Jnr. (2007). Strategic management: formulation, implementation and control (10th ed.). Mc Graw-Hill/Irwin.

Pillania, K. (2008). Strategic issues in knowledge management in Small and Medium Enterprises. Knowledge Management Research \& Practice, 6(4), 334-338. https://doi.org/10.1057/kmrp.2008.21

Sababu, B. M. (2007). Strategic management, the analytical approach (1st ed.). Jomo Kenyatta University, Kenya.

Tejeda, J. J., \& Punzalan, J. R. B. (2012). On the misuse of Slovin's formula. The Philippine Statistician, 61(1), 129-136.

Thompson, A. A., \& Strickland, A. J. (2003). Strategic management: concepts and cases. McGraw-Hill.

Tunji, S. T. (2013). Effective internal controls system as antidote for distress in the banking industry in Nigeria. Journal of Economics and International Business Research (JEIBR), 1(5), $106-121$.

Ursachi, G., Horodnic, I. A., \& Zait, A. (2015). How reliable are measurement scales? External factors with indirect influence on reliability estimators. Precedia Economics and Finance, 20(1), 679-686.

https://doi.org/10.1016/S2212-5671(15)00123-9

Wheelen, T. L., \& Hunger, J. D. (2012). Strategic management and business policy: towards global sustainability (13th ed.). Prentice Hall.

Woodridge, B., \& Floyd, S. W. (1990). The strategy process, middle management involvement, and organisational performance. Strategic Management Journal, 11(3), 231-241. https://doi.org/10.1002/smj.4250110305

Yunus, M., Moingeon, B., \& Lehmann-Ortega, L. (2010). Building business models: Lessons from the Grameen Experience. Long Range Planning. https://doi.org/10.1016/j.lrp.2009.12.005 